\title{
ACCESSING HIGHER EDUCATION LEADERSHIP: TOWARDS A FRAMEWORK FOR WOMEN'S PROFESSIONAL DEVELOPMENT
}

\author{
A. Moodly* \\ Deputy Dean, Faculty of Education \\ e-mail: amoodly@ufh.ac.za
}

\section{N. M. Toni*}

Director: Teaching and Learning Centre

e-mail: NToni@ufh.ac.za

*University of Fort Hare

Eastern Cape, South Africa

\section{ABSTRACT}

Women's academic pathways are not linear and chronological in an age-related pattern. This requires a framework that accommodates the unique personal circumstances of women in accessing leadership. The gendered nature of Higher Education Institutions (HEIs) that emanates from the institutional culture and the perception of leadership in women as a culture of service has impacted negatively on women and leadership. Continuous interventions can address the shortage of women representation and also address the cultural and environmental factors that create barriers. The authors present a theoretical overview based on literature and previous empirical research, and propagate that a framework should be put in place towards a life-cycle continuum of professional development for women. Based on Huberman's Teacher Life Cycles stages, it is particularly advanced to contend with factors as identified that impact on the dearth of women in HE leadership positions.

Keywords: gendered cultures, culture of service, lack of support structures, Huberman's teacher lifecycle stages

\section{INTRODUCTION}

In previous work (Moodly and Toni 2015a, 45) the researchers assert that in spite of progressive policies in the South African higher education system women are still confronted with the challenge of not breaking the glass ceiling when it comes to accessing leadership positions. We therefore found it imperative to delve into the trajectory of women's life and career developmental needs and achievements in their ascension into leadership roles. It is also important to interrogate the various aspects and perceptions put forth as contributing factors to the dearth of women leaders in higher education. The limited number of women applying for 
senior and leadership positions (Litzky and Greenhaus 2007); insufficient support for professional effectiveness and career progression; and institutional cultures that favour men over women (Tessens, White and Web 2011), among others, are some of the contributing factors. It is also argued by some (Johnson 2014; Tessens et al. 2011; Litzky and Greenhaus 2007) that universities are gendered organizations. Johnson (2014) speaks of women being relegated to care work, and women themselves having to deal with knowing that being a woman came with socially prescribed work, activities and actions. Tessens et al. (2011), in their analysis of developmental needs and support of women in Australia observed a pattern of women mostly occupying the roles of DVCs of Community Engagement or Teaching and Learning instead of DVCs International Affairs. The phenomenon is also evident in the positions of Executive Deans of disciplines of Natural and Physical Sciences, as well as Deans of Information Technology being occupied by mostly men. These realities affirm the need to encourage women to broaden their roles in areas that strengthen access to the hierarchy within HE leadership.

It flows from the foregoing that structured plans and support mechanisms should be put in place to transform higher education leadership to include more women. Our quest for the development of a framework of a life-cycle continuum would therefore serve as a compass for professional development of women into HE leadership.

\section{EXPERIENCES, REALITIES AND THE TRAJECTORY OF WOMEN IN HIGHER EDUCATION LEADERSHIP}

It has been established that regardless of the steady increase of female enrolments and employment in HE, underrepresentation of women starts at senior lecturer level (Moodly and Toni 2015a). It is for this reason that we explore phases and related experiences and life/career trajectory of women in HE.

Research indicates that higher education leaders are usually sourced from within the HE context and have come through the rank and file in this regard. A desktop overview of VCs in the 26 universities in SA (conducted in March and June 2016) indicated that most (at least 20) came through the academic rankings before taking up the positions of VCs in the respective SA universities. Of the 26 current vice-chancellors, the desktop review indicates that four are women, a total percentage of 15.38. This is a drop of two percent since a desktop review conducted in 2014 by Moodly (2015). Though the number of universities had increased from 23 to 26, the number of female vice-chancellors remained at four (in 2014 and 2016 respectively). 


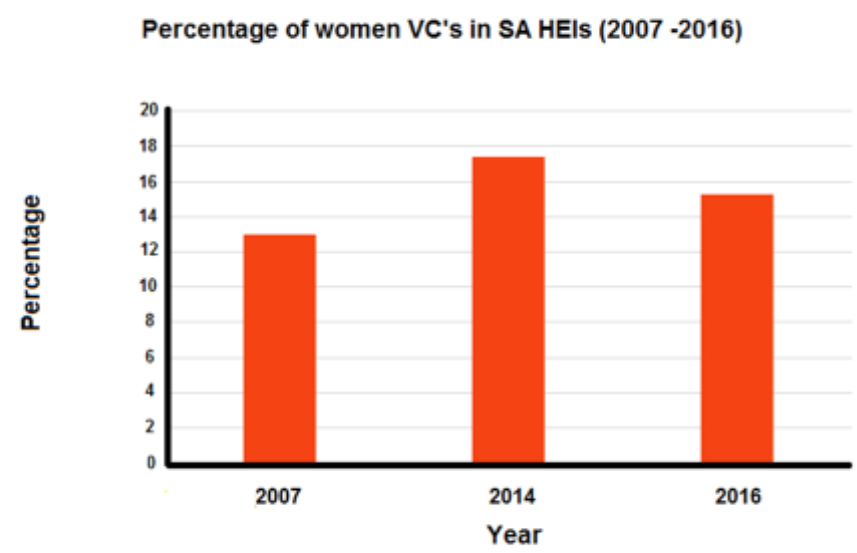

Figure 1: Percentage of women VC's in SA HEls (2007-2016)

Research by Moodly and Toni (2015a) indicated a lack of women as role models in leadership in the higher education sector, and identified a lifecycle continuum along which women develop to become role models and leaders. Moodly and Toni argue that cognisance should be taken of this life-cycle continuum within a context of policy, to facilitate the development and enhancement of women as leaders in higher education. Further to this, Moodly and Toni (2015b), identified structural and cultural factors that inhibited the promotion of women to leadership positions within HE. The authors identified these factors within the institutional culture(s), the micro-environment (family), and the surrounding environment. Together with this, it was also argued that 'a lack of accountability on the part of Higher Education Institutions in the implementation of national and international imperatives around women and leadership’ also inhibited the advancement of women in HE leadership.

\section{THE CONTEXT OF LEADERSHIP IN HIGHER EDUCATION: GENDERED CULTURES AND CULTURE OF SERVICE}

\section{A hostile environment: Institutional cultures}

The scarcity of women in positions of power in higher education is a phenomenon not only limited to the South African context. Husu (2001 in Tessens et al. 2011, 655) posits that 'women's under-representation in positions of power and prestige in academia appears to be a universal phenomenon ... women at the top see structures and men's role as a problem on the way up, while men tend to blame women themselves (saying they do not apply to a sufficient 
degree)'. Among the many factors that contribute to fewer women in higher education leadership, Moodly and Toni (2015a) allude to attitudinal and organizational biases against women. Universities thus continue to be perceived as gendered institutions, as also highlighted in Acker (2010). A further explication of the organizational biases is what Gallant (2014, 204) terms 'similarity attraction' whereby institutions attract and employ people similar to their predecessors. This practice perpetuates the status quo of gendered organizational cultures that focus on male values and networks. Thornton (2008 in Tessens et al. 2011), asserts that women who seek promotion to senior management positions often come to realize how male-dominated universities continue to be. Another contributing factor is the challenge of retaining those women who are already in management positions, thus making it even more difficult to drastically increase the number of women in leadership positions.

De la Rey (1999) in her doctoral thesis refers to literature that describes the institutional culture of universities as 'masculinist'. The masculinist culture of universities is a problem for women academics as HEIs are organised in ways that privilege masculinities. The recurrent gender biases against women can also be equated to gate keeping. According to Van den Brink (2009) as cited by Tessens et al. $(2011,655)$ gate keeping involves 'being part of or having connections with the dominant group'. Regardless of the masculine culture, skills needed for effective leadership in HE are not necessarily gendered. White et al. $(2010,657)$ mention strategic vision, strong research reputation, resilience, collaboration, among others, as some of the skills required to be an effective university manager.

\section{LEADERSHIP AS A CULTURE OF SERVICE}

Higher education, in its nature, is a context characterised by research productivity. Research productivity and evidence thereof through published works plays a pivotal role in ascension to leadership positions. This is where most women fall short in accessing higher education leadership positions. Research outputs of men in peer-reviewed publications exceed outputs by women (Obers 2014). In reflecting on her transition from a College of Education to be an academic at a university, Mahope (2014), for example, recounts prioritising and/or putting emphasis on teaching responsibilities more than research and publishing. She further mentions being among black women academics who tended to put their careers on the backburner to focus on their children and families. Whilst their male counterparts would spend many hours on their research, women would focus on families when not busy with teaching and administration that accompanies it. Acker $(2010,136)$ alludes to 'conventional ideas' of women as responsible for the emotional well-being of others persisting within the academic field and 
its leadership.

The caring nature of women is also reflected by their choice of disciplines (Acker 2010). Obers $(2014,113)$ postulates that 'women tend to gravitate to disciplines which may not foster high levels of research productivity; ... are mostly still seen as primary care-givers and often interrupt their career path due to child-bearing ...' An interesting factor in Johnson's (2014) research on women who achieved administrative and leadership positions at five sub-Saharan African universities is the fact four of the five women began their careers as teachers and the fifth as a nurse. This aspect leads to questions or perceptions about possible differences, if any, in leadership styles of men and women.

According to authors such as Litzky and Greenhaus (2007) and Acker (2014), women enter management by 'accident', rather than through engagement in leadership careers. In a study of experiences of Canadian women academics in 'lower middle management positions', Acker $(2014,73)$ found that women were not attracted to 'leadership careers' as they found the work they did extremely stressful. She found that there was no preparation, assistance and mentorship to the women whom she described as 'dedicated and hard-working individuals'. Ackers cites researchers such as Morley and Smith (in Acker 2014), who observe that although 'new management' opportunities for women at universities present themselves, there have also been changes in the university environment. Increasingly universities are subject to 'entrepreneurialism, managerialism and performativity’ (Ward 2012, in Acker 2014, 74). Morley and Smith (in Acker 2014) observe that this changing environment has a harmful effect on women. These opportunities are not always in the academic arena, and are characterised by a 'blend of administration and academe' (Whitchurch 2008, in Acker 2014, 74), and are believed to be a new form of an 'old practice of women taking on service responsibilities', which is only in the interest of the 'corporate university' (Fitzgerald and Wilkerson 2010 in Acker 2014, 74; Morley 2013 in Acker 2014, 74). Acker also cites Pyke (2011) who similarly argues that women take up 'service work' in addition to their academic workload, due to a strong sense of 'good citizenship, altruism and civic obligation'. Women interviewed by Acker, reflected their management roles as gendered in that their managers were men as their 'superiors', they played a 'helper' role, and there were 'inflated expectations' that they were carers. Even though they played a 'glue work role', women were not recognized for this as part of their working life pattern (Eveline 2004, in Acker 2014, 79). Due to the stresses experienced within lower middle management positions (human resources challenges, lack of resources, gendered work in terms of 'cleaning up messes', long days in the office, inclusive of teaching obligations), as well as meeting family concerns, the women interviewed were reluctant to take 
up leadership as careers. Many found that indirectly, their family life perpetuated the imbalance of work and family, in that the family support system compensated for their absence. Either the children or partners would take over their share of housework. The danger is that the family structure may condone and 'subsidize overwork' (Acker 2014, 80). Acker argues that it is the 'casual way' of filling in lower middle management positions that compromises women's careers, making leadership unattractive. There is an 'unclear dividing line' in identifying 'service and administration'. Usually after a stint in the position (of middle management) women returned to academia. Acker concludes that there is a need for 'strong institutional supports', 'planned' 'long-term managerial careers' through 'succession planning and leadership development for early- or mid-career women academics’. A more careful approach to 'recruitment, retention and release' is also recommended by Acker.

\section{SUPPORT STRUCTURES /MENTORING}

Among the unintended consequences of having a culture that favours men is a lack of professional support and networks for the benefit of women. The need for 'developing stronger support networks for women’ is also emphasised by Acker (2010, 147). Women are perceived to have limited access to strong and extended networks as enablers to positions of power in HEIs (Obers 2014). Gamble and Turner $(2015,84)$ mention mentorship and networking to be the most helpful in breaking the glass ceiling for women. The existence of the glass ceiling for women is also reflected in literature by amongst others Morley (2013; 2014), and authors such as MacNae and Valli $(2015,294)$ who cite gatekeeping as a barrier to the advancement of women; 'women perceived men as gatekeepers in leadership appointment process'. They also cite women who spoke about experiencing 'limited career progress due to male gatekeepers' and 'intensive surveillance (by men) after being promoted'. Participants in Tessens et al.'s (2011, 663) research identified peer-support, supervisors and networks that are informed by effective organisational skills and administrative support, as vital strategies for career advancement. It is important to note the multidimensional nature of effective mentorship. Tran $(2014,310)$ speaks of a 'portfolio of mentors'. This implies having mentors and networks that extend beyond one’s organisation. Getting the relevant support and mentoring very early in their careers (post graduate level) is very crucial in shaping career trajectories of women.

In their multi-country study that examined cross cultural perspectives on gender and management in universities, White et al $(2010,656)$ identified what they call 'gendering in the support received in moving into senior management'. They claim that men tended to receive mentoring and grooming from senior management unlike women who are mainly supported by 
their families and junior people within the institution. Gamble and Turner $(2015,98)$ recommend 'diversity driven mentoring and leadership programs'. Such programmes may assist leaders to appreciate the value of diverse environments. The appreciation of diversity, in the case of institutions being gendered spaces may also assist those in power to be sensitive to the plight of women struggling to access structures and positions of power.

\section{PROFESSIONAL CAREER DEVELOPMENT: FRAMEWORK OF PHASES}

Theorists have always suggested that both men and women go through various phases/stages and pathways in their career-trajectories, also known as professional development, and that the final stages/phases are dependent on experiences during the initial and intermediate phases. These theories have evolved over the years, in the earlier period viewing development from a psychological perspective (Kohlberg's Moral Development; Erikson's Psychosocial theory; Hunt's Cognitive Developmental Theory; Maslow's Hierarchy of Needs, for example). More current theorists have focused on frameworks that have been developed for understanding the professional development (of the teacher) throughout the course of their career such as Berliner (1994); Fessler (1995); Glaser (1996); Feiman-Nemser (1983); Hubermann (1995); Steffy and Wolfe (2001) (in Broad and Evans 2006, 9). For women, literature reflects that these phases are neither linear nor chronologically age-related, but are rather non-linear and non-chronological (Acker 2014; Johnson 2014; Mahope 2014).

\section{Gender and career development}

A criticism of career development theories and models is that research was conducted by men using male participants (Levinson, Havinghurst, and Erikson, for example). These theorists 'describe life as a series of stages linked to specific ages and occurring in sequence, with each stage having developmental tasks, and patterns of stability and transition to the next stage' (Kerka 1992, 1). Yet there are significant differences in career cycles between men and women, and they do not necessarily follow a clear chronological and age-related pathway. Kerka argues that 'changes in the composition of the workforce and changing work values' have also forced theorists to question the validity of chronological-based models. Much emphasis is placed on balance between family and work interrelationships, and this requires 'new ways' of viewing 'life span and career development'. Beauregard (2007, 3) also argues that 'values and attitudes related to the balancing of work and family' amongst others, have influenced a change in employment patterns of women, with young women (and men) appearing to 'desire a more integrated approach to work and family, rather than a dominance of one over the other'. 
Beauregard cites researchers who suggest that 'young women take family responsibilities into account when choosing occupations'. Marks and Houston (2002) is cited by Beauregard (2007, 4), for example, whose research have found that social pressure on girls determined their career choice, and that 'high achieving' girls 'were more likely to choose occupations that more easily combines work and family, such as "nursing and teaching", rather than "science and technology”, which are more male-dominated occupations, thereby perpetuating the 'occupational sex segregation'.

Kerka $(1992,1)$ asserts that 'women's lives are more closely characterized by social interaction', 'personal relationships and attachment', whereas developmental models usually define 'maturation as separation and individuation' (Gilligan cited by Eastmond 1991 in Kerka 1992). Women's lives are not as linear as models depict, as careers can be interrupted by 'marriage and childrearing', amongst other factors. Kerka (1992, 1) cites Eastmond (1991) who states that 'women may accomplish the same developmental tasks as men but in different periods of the life cycle'. Much more than men, 'women's career and life choices are affected by different sex-role socialization and available opportunities' (Gutek and Larwood 1987, in Kerka 1992, 1). In addition to challenges that women face in career progression, they also often experience conflict between split careers as primary carers and professionals. This can result in women experiencing a revitalized growth and exploration stages in their 40s and 50s when children leave home. Some women find themselves as 'early career' academics at the age of 50 (Msimanga, 2014).

It is for this reason that models need to be reviewed so as to consider the experiences of women's life-cycles. These should consider the 'relationship element', including 'the interweaving of the individual, family and work'.

\section{PROFESSIONAL DEVELOPMENT OF TEACHERS}

Broad and Evans $(2006,3)$ focused on the professional development of experienced teachers arguing that it has not been given the attention it deserves in 'professional development literature'. The researchers argue that there are 'phases and stages' with an 'implicit developmental aspect'. They postulate that a 'single, linear pathway or career trajectory for teachers' does not exist and that the pathways are rather 'cyclical and even recursive'. Due to different 'unique learning needs', the need is for 'differentiation of professional development practices'. Due to the 'varied and unique professional needs' relative to 'personal and professional circumstances, histories, and contexts and not merely due to career length or life stage' account must be taken of 'matching appropriate professional development provision to 
particular professional needs'. In this regard Broad and Evans refer to the 'psychological stage theories' which outline distinctive and qualitative differences in thinking and cognition at various stages of development (e.g. Kohlberg's moral development; Erikson’s Psychosocial theory; Hunt's Cognitive Developmental Theory; Maslow's Hierarchy of Needs). These psychological theories underscore the growing sophistication and capacity to move beyond the self as learners mature. These understandings of adult development and learning support the professional development research that suggests that teachers' self-affirmation and selfactualization needs are key aspects of their personal learning and professional development. A number of frameworks have been developed specifically to help understand the stages of teachers' professional development throughout the course of a career (e.g. Berliner 1994; Feiman-Nemser 1983; Fessler 1995; Glaser 1996; Guskey 1995; Hammerness et al. 2005; Huberman 1995; Steffy and Wolfe 2001), all cited in Broad and Evans (2006). These frameworks suggest potential career cycle trajectories, with varying needs at different stages. They also remind us that the sequence and timing of these stages may be variant, uniquely individual, and recursive and spiralling rather than linear.

\section{HUBERMAN'S TEACHER LIFE CYCLE STAGES}

Huberman's, teacher life cycle stages - 1995 (in Broad and Evans, 2006) is discussed as an appropriate model to frame a life-cycle continuum model for women towards HE leadership. As indicated previously, though not exclusively so, most vice-chancellors came through the academic ranks. The model framework would also be situated within the Higher Education environment. Huberman identified three stages in the teachers' life cycle (as linked to professional needs). Phase 1 was described as the 'career entry' phase, also identified by Steffy and Wolfe (2001, 16), and known as the novice phase (Huberman, in White 2008). The primary concern of this phase is 'surviving' and not being seen as incompetent. The second phase, known as the 'mid-career phase' focuses on growing in self-confidence (Steffy and Wolfe 2001), reflecting and stabilizing. This is also the phase in which confident teachers settle into a predictable pattern and experiment with new approaches and activities. Reflecting during this phase could entail 'taking stock' where teachers contemplate their worth in terms of 'their past work' and plans for continuation. It is during this period that satisfaction/dissatisfaction with perceived progress or lack of progress sets in. Broad and Evans (2006) purport that at this stage, teachers are aiming to increase their skills and effectiveness and to look beyond the classroom to collaborative projects and activism. Stage three refers to the late-career in which either serenity or disengagement sets in. Serenity emanates from satisfaction within the teaching 
career, and disengagement usually stems from focusing on retirement and life beyond teaching. Emotional distance from the teaching environment can also occur at this stage. Huberman (in Broad and Evans 2006, 9) discovered that it is typical that between 12-20 years of experience, 'the teacher engages in self questioning' and may consider a career change as part of a broader 'life review'. If the answers to the questions are positive, then serenity and continued growth can follow. If disappointment or dissatisfaction occurs, then conservatism or even disengagement can be the outcomes.

There are numerous models proposing a continuum of professional learning, amongst others, Feiman-Nemser (2001, in Broad and Evans 2006) and Steffy and Wolfe (2001) as previously mentioned. These models all highlight the need to be attentive to teachers' needs at different stages which has implications for continued development and growth (in teaching in these cases). Feinmen-Nemser (2001, in Broad and Evans 2006), emphasises the importance of matching of appropriate professional development provision with particular, individual, contextualized professional needs. These are considered in the context of a model framework towards women's professional development towards leadership in a higher education context.

\section{DISCUSSION}

In this section the literature review on gendered cultures within organizations, inclusive of the need for support structures are brought together with the discussion on the need for a framework to specifically support women towards HE leadership. As indicated, the continuum for women does not necessarily reflect a linear and age-related chronology, as life events (marriage, childrearing, and other factors) also impact on professional development decisions. This together with academic pressures (teaching load and publication, for example), impacts greatly, in the context of institutions characterized by a strongly gendered culture and lack of support systems. The framework below is not a pre-determined, linear path, but highlights aspects to be considered in capacitating women. Neither is it linear in the phases outlined (as in phase one does not necessarily pre-cede phase two, for example). More than the phases are the interventions highlighted which are not limited to a particular phase. The framework talks to policy implementation that needs to be accelerated in order to create a non-gendered institutional environment that is conducive to women's growth in leadership. Policy should also facilitate rather than exploit women's style of service leadership which tends to limit women to middle management, rather than elevate them to executive levels. 


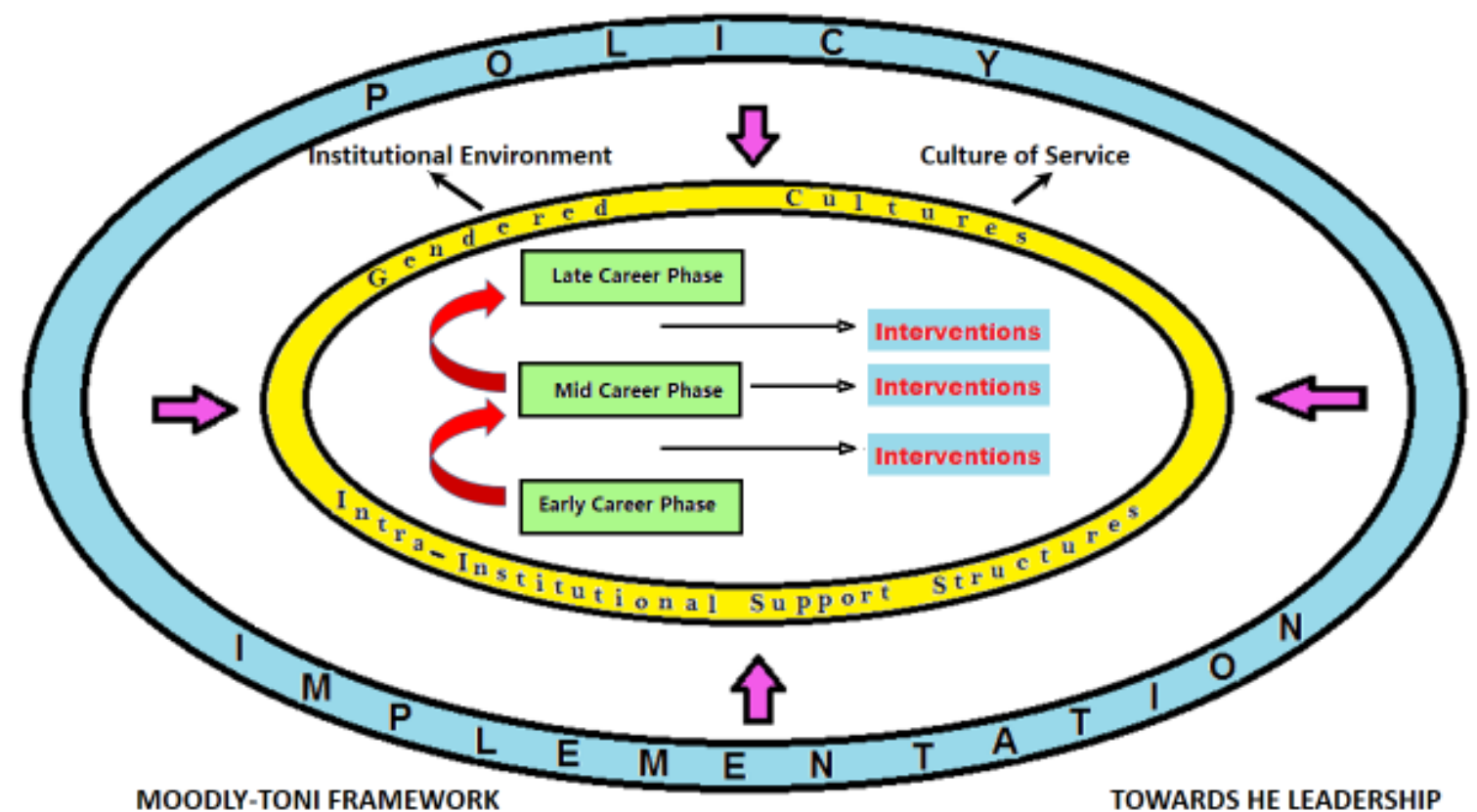

Figure 2: Moodly-Toni framework - towards he leadership

\section{POLICY IMPLEMENTATION}

In addressing the overarching barriers of gendered cultures and intra-institutional support structures within Higher Education, Moodly (2015), and Moodly and Toni (2015a), reiterate that it has to be in the context of existing policy. Enabling policies are already in place to facilitate women's access to higher education and leadership. These policies provide the guidance and map out the issues that need to be addressed to enable women to access and take up positions of leadership. Policy guides how the issue of gendered cultures should be addressed and provides a mechanism for each and every individual within the organization to participate within platforms that address this barrier. We highlight that institutions fail to implement these policies. Policy implementation can facilitate addressing barriers of gendered cultures as well as the lack of intra-institutional support for women within HEIs. This is a fundamental issue that cannot only form part of discussions on women and leadership, but affects the very character of HEIs. It should therefore be part of any model that orientates new staff/students into the institution, as well as find itself as part of all platforms of activity within the institutions, albeit recruitment, retention and promotions (at all levels). It should be given a space in both academic circles (symposia/conferences/lectures), as well as administrative and management arenas, when implementation of policies is reviewed and practised. There should be a visible shift in the culture of the institution, in how access to opportunities for women are introduced and supported by all levels and persons within the organisation. Accountability, as previously reiterated by Moodly and Toni (2015a) is key to the implementation of existing policies that 
facilitate women's access to leadership, as well as to introduce policy where institutions are silent on it. In terms of a model framework, the issue of addressing gendered cultures has to permeate all levels of the model so as to conscientise women and men alike. Policy implementation should also guide the manner in which lower middle management positions and distinguishes between service and administration. Strong institutional support, and planned, long-term managerial careers through succession planning and leadership development for early- or mid-career women academics should also be guided by policy, together with a careful approach to recruitment, retention and release.

\section{CULTURE OF SERVICE}

This practice, as previously indicated forms part of the gendered culture of institutions. Women tend towards the caring and 'service' nature of leadership, and this is perpetuated by the notion that women are caregivers. The model framework should also address leadership and the nature of leadership required by HEIs. Role models and mentors on leadership should be identified in order to orientate and alert/sensitise women to the type of leadership required in the $\mathrm{HE}$ environment. Opportunities and nurturing of alternative practices in leadership should be gradually introduced within the model, at a phase where women feel comfortable to look at themselves as potential leaders at senior management levels. Considering the discussion on gendered cultures and culture of service that would be fundamental to the model, the following section delves in more detail into the phases of the model.

\section{Phase 1: Early career}

At this stage women may be dealing with issues of competency (questioning) and building academic skills. It is also possible at the same time that women are dealing with family pressures (marriage/ younger children), and coming from a pressured family context in this regard. Interventions at this stage, in our view, require a definitive leader who will provide guidance in terms of settling the person into their environment. This calls for a leader who is already conscientised and sensitized to the issues of a gendered environment, and is able to provide initial support to the novice to identify the skills and tools required to acclimatise to the demands of HE. As reflected in the literature, getting the relevant support and mentoring very early in their careers, is very crucial in shaping career trajectories of women. At this stage the leader may:

Identify a few mentors to play particular roles (academic skills development) - in view of the multidimensional nature of effective mentorship. 
Identify support groups on issues of balancing family and academic life.

Encourage co-writing and co-supervision with peers.

Encourage a plan of career development (though not necessarily as a leader as this may be too soon).

Encourage workshop/seminar and conference attendance in line with the identified career path needs.

Identify professional support and networks for the benefit of women.

\section{Phase 2: Mid-career}

This phase can be considered according to various scenarios which are dependent on how policy has been implemented and practised in addressing gendered cultures and service - culture bias within HEIs.

\section{Scenario 1}

This scenario considers the possibility of women working towards the mid-career phase and who are overloaded with a teaching burden, and have not addressed the research requirements towards promotion/executive leadership. Some may be in middle management leadership positions, caught up in service leadership (in the context of gendered cultures) and possibly family tensions (balancing family and career). It may be that at this stage women are selfreflecting as per Huberman's phase 2 and find themselves uncomfortable with their current status. It may be that a leader (as described in phase 1) has been absent in guidance from Phase 1 to Phase 2. Ten years into their career, self-reflection becomes a period of despondency. It is suggested that the interventions recommended in Phase 1 can still effectively be implemented in scenario 1, with an amended programme that includes elements identified in scenario 2 as follows hereafter.

\section{Scenario 2}

If the issues identified in Phase 1 have been implemented, women may not be experiencing the tensions as outlined in scenario 1. Interventions can be elevated and include:

Continued networking and expansion to exposure to role models in management and leadership through shadowing.

Continued peer-support.

Continued research (through teams or as an individual).

Supervisors and networks that are informed by effective organisational skills and administrative support.

Courses towards skills for effective university management and leadership: Addressing strategic 
vision, research, resilience, collaboration, among others, as some of the skills required to be an effective university manager.

\section{Phase three: Late career}

Based on interventions as outlined in phases one and two, and provided that transformation of the environment in terms of culture has been effected, it may be that women reach a stage of serenity, and become more at ease and capacitated to actively pursue and take on leadership roles. This may not be a clear chronological and linear transition as outlined, but the model attempts to acknowledge the life cycle continuum of women and to facilitate a more realistic and tangible approach to address the inequities.

\section{CONCLUSION}

The article emphasises that a life-career advancement continuum particular to women exists and needs to be considered in policy implementation towards the advancement of women in HE leadership. Further, a lack of accountability on the part of HEIs in the implementation of national and international imperatives around women and leadership has also inhibited the advancement of women in HE leadership. This article attempts to acknowledge this continuum and to provide a framework in which leadership within women can be nurtured, encouraged and supported. It puts forth fundamentals in facilitating this through policy implementation that transforms the gendered culture of HEI environments and suggesting support structures. Further, it contextualises a life-cycle continuum pertaining to women in particular, and suggests various interventions within various stages of the lifecycle. These phases are not necessarily chronological and linear, and the model in itself needs to be adaptable to the individual's growth path. The working environment encroaches more and more on family life and family support often perpetuates the acceptance of worktime eating into family time. Families that are supportive sacrifice family time in order to ensure a successful career of either parent, for example, and this model does not challenge the practice (though it does not mean that the authors concur with it either). The scope of the changing work-family milieu where it is acceptable to bring work home or work after hours and weekends, has not been the scope of this research/paper.

The authors acknowledge the multiplicity of factors that contribute to the slow advancement of women to the highest echelons of HE leadership, and the perception that women themselves are often reluctant to put themselves forward for promotion. However, institutional cultures that are biased against women contribute to the perceived glass ceiling phenomenon that the article attempts to address. The model is hence offered as one possibility 
that could contribute to the enhancement of professional development opportunities towards leadership, and not as a panacea to all professional challenges in HE. The model in itself cannot be implemented in isolation of addressing the status quo, as it may then in itself become a superficial framework, rendering women ineffective and setting them up for failure in HEIs that ad infinitum may be characterised by strong notions of masculinities and perceptions of women as fulfilling leadership as a culture of service.

The non-chronological and non-linear nature of the model characterises the unique personal circumstances of women in HE notwithstanding similarities in organizational cultures. This implies that interventions would not necessarily always start at early career levels. Midcareer women could also derive benefits from the interventions taking cognisance of the two scenarios explored. Effective implementation of interventions before the late career stage could possibly accelerate serenity and boost confidence in career pathing of women, and increase the number of women leaders in HE.

Throughout the literature, and thus strongly reflected in the interventions proposed in the model is strong institutional support, within a long-term career plan, comprising of succession planning and leadership development. The model would need to be reviewed so as to consider the experiences of women's life-cycles, inclusive of the relationship element including 'the interweaving of the individual, family and work'.

\section{LIMITATIONS OF THE STUDY}

It is acknowledged that the focus is on the micro (institutional environment) and does not consider the macro (family and societal environment) when advancing the model. The framework is limited in this context. Furthermore, the framework works within the status quo rather than questions the workload that eats into family time and can be dependent on family supportive structures, or the decision not to have a family in favour of a demanding career.

\section{REFERENCES}

Acker, S. 2010. Gendered games in academic leadership. International Studies in Sociology of Education 20(2): 129-152.

Acker, S. 2014. A foot in the revolving door? Women academics in lower-middle management. Higher Education Research \& Development 33(1): 73-85.

Beauregard, T. A. 2007. Family influences on the career life cycle. In Career choice in management and entrepreneurship: A research companion, ed. M. Ozbilgin and A. Malach-Pines. Edward Elgar Press.

Broad, K. and M. Evans. 2006. A review of literature on professional development content and delivery modes for experienced teachers. Initial Teacher Education Program, Oct.

De la Rey, C. 1999. Career narratives of women professors in South Africa. Doctoral Thesis. University 
of Cape Town.

Gallant, A. 2014. Symbolic interactions and the development of women leaders in higher education. Gender, Work and Organization 21(3): 203-216.

Gamble, E. and N. Turner. 2015. Career ascension of African American women in executive positions in postsecondary institutions. Journal of Organizational Culture, Communications and Conflict 19(1): 82-101.

Johnson, A. 2014. Performing and defying gender: An exploration of the lived experiences of women higher education administrators in sub-Saharan Africa. Educational Management Administration \& Leadership 42(6): 835-850.

Kerka, S. 1992. Life cycles and career development: New models. Eric Clearinghouse on adult career and vocational education. Columbus $\mathrm{OH}$.

Litzky, B. and J. Greenhaus. 2007. The relationship between gender and aspirations to senior management. Career Development International 12(7): 637-659.

Mahope, S. S. 2014. Becoming a new kind of professional: A black woman academic caught in a transition. South African Journal of Higher Education 28(6): 1986-1998.

McNae, R. and K. Vali. 2015. Diverse experiences of women leading in higher education: Locating networks and agency for leadership within a university context in Papua New Guinea. Gender and Education 27(3): 288-303.

Moodly, A. 2015. Gender equity in South African Higher education leadership: Where are we twenty years after democracy? Journal of Social Sciences 42(3): 229-238.

Moodly, A. and N. Toni. 2015a. Women's access towards higher education leadership: Where are the role models? Journal of Social Sciences 45(1): 45-52.

Moodly, A. and N. Toni. 2015b. Women's voices of and on leadership in higher education. Paper presented at the Global Research and International Services (GRDS) $7^{\text {th }}$ International Conference on Teaching, Education and Learning (ICTEL), 10-11 October 2015. Pointe aux Piments, Mauritius.

Morley, L. 2013 The rules of the game: Women and the leaderist turn in higher education. Gender and Education 25(1): 116-131.

Morley, L. 2014 Lost leaders: Women in the global academy. Higher Education Research and Development 33(1): 114-128.

Msimanga, A. 2014. Too late to come back? The paradox of being a 50-year-old 'early career' black female academic. South African Journal of Higher Education 28(6): 2013-2026.

Obers, N. 2014. Career success for women academics in higher education: Choices and challenges. South African Journal of Higher Education 28(3): 1107-1122.

Steffy, B. E. and M. P. Wolfe. 2001. A life-cycle model for career teachers. Kappa Delta Pi Record 38(1): 16-19.

Tessens, L., K. White and C. Web. 2011. Senior women in higher education institutions: Perceived development needs and support. Journal of Higher Education Policy and Management 33(6): 653-665.

Tran, N. A. 2014. The role of mentoring in the success of women leaders of color in higher education, mentoring and tutoring. Partnership in Learning 22(4): 302-315.

White, K., S. Riordan, O. Ozkanli and J. Neale. 2010. Cross cultural perspectives of gender and management in universities. South African Journal of Higher Education 24(4): 646-660.

White, R. 2008. Teachers' professional life cycles. International House Journal of Education and Development 24. http://ihjournal.com/teachers-professional-life-cycles (accessed 1 June 2016). 